\title{
Recurrent Disease in Juvenile Differentiated Thyroid Carcinoma: Prognostic Factors, Treatments, and Outcomes
}

\author{
Jasna Mihailovic $^{1,2}$, Katarina Nikoletic ${ }^{1}$, and Dolores Srbovan ${ }^{1}$ \\ ${ }^{1}$ Department of Nuclear Medicine, Oncology Institute of Vojvodina, Sremska Kamenica, Serbia; and ${ }^{2}$ Technical Faculty \\ "Mihajlo Pupin” Zrenjanin, University of Novi Sad, Novi Sad, Serbia
}

The overall prognosis in pediatric differentiated thyroid carcinoma (DTC) is excellent. Recurrent disease is frequent, however, and requires additional treatment. We analyzed the probability of recurrence, prognostic factors, treatment, and outcome of juvenile DTC. Methods: Fifty-one DTC patients (32 girls and 19 boys; $\leq 20$ y old; mean age, $16.5 \mathrm{y}$ ) were treated with ${ }^{131}$ ( (radioiodine, or radioactive iodine [RAI]); the median follow-up was $10 \mathrm{y}$. Patients underwent different initial treatments: 46 patients received total thyroidectomy and RAl, 3 patients received total thyroidectomy, and 3 patients received subtotal thyroidectomy. The probability of recurrence and prognostic factors were tested with the Kaplan-Meier method. Results: Initially, 36 of 51 patients achieved complete remission, 14 of 51 achieved partial remission, and 1 of 51 had progressive disease. By the follow-up, 11 of 51 patients $(21.6 \%)$ had developed recurrent disease; the median appearance time was 4 y (range, 1$15 \mathrm{y})$. The probabilities of recurrence were $16.7 \%$ at $5 \mathrm{y}, 22.3 \%$ at $10 \mathrm{y}$, and $33.3 \%$ at 15 and 23 y after the initial treatments. Factors that were strongly predictive of recurrence were age $(P=0.001)$, initial treatment $(P=0.0001)$, and tumor multifocality $(P=0.011)$. Sex, nodal metastases at presentation, distal metastases at presentation, histologic type of the tumor, $T$ stage, and clinical stage had no influence on relapse $(P=0.180, P=0.786, P=0.796, P=$ $0.944, P=0.352$, and $P=0.729$, respectively). Patients with recurrent disease, partial remission, and progressive disease were retreated, with either surgery or surgery and RAI, receiving cumulative activities of up to $40 \mathrm{GBq}$. The overall outcome in our patients was excellent: $90.2 \%$ complete remission, $3.92 \%$ partial remission, $1.96 \%$ stable disease, $1.96 \%$ disease-related death, and $1.96 \%$ another cause of death. Conclusion: Younger age at diagnosis, less radical primary surgery without subsequent RAI, and tumor multifocality are factors that are strongly prognostic for recurrence. For reducing the rate of relapse and improving surveillance for recurrent disease, total thyroidectomy followed by RAl appears to be the most beneficial initial treatment for patients with juvenile DTC. The use of RAl seems to be safe, with no adverse effects on subsequent fertility and pregnancy or secondary malignancy.

Key Words: differentiated thyroid carcinoma; juvenile; radioiodine therapy; recurrence; outcome

J Nucl Med 2014; 55:710-717

DOI: 10.2967/jnumed.113.130450

Received Aug. 4, 2013; revision accepted Nov. 19, 2013.

For correspondence contact: Jasna Mihailovic, Department of Nuclear Medicine, Oncology Institute of Vojvodina, Put dr Goldmana 4, Sremska Kamenica, 21204 Serbia.

E-mail: jasnans@eunet.rs

Published online Apr. 10, 2014.

COPYRIGHT (c) 2014 by the Society of Nuclear Medicine and Molecular Imaging, Inc. uvenile differentiated thyroid carcinoma (DTC) (specifically, papillary thyroid cancer [PTC] and follicular thyroid cancer) is a rare malignancy, accounting for $0.5 \%-3 \%$ of childhood carcinomas (1). As one of the most common endocrine neoplasms, it occurs with incidences of $1 \%$ in prepubertal children and $7 \%$ in adolescents (2). The Serbian Cancer Registry reported 42 newly diagnosed cases of DTC in patients 19 y old or younger between 1999 and 2010, with a female-to-male ratio of 3.7:1 (3,4).

DTC in childhood presents with aggressive clinical findings; $60 \%-80 \%$ of patients have cervical nodal involvement, often associated with distant metastases but without an overall increase in mortality compared with that in adults (5-8). The risk for cancer relapse, however, is high, with more frequent local recurrent disease in children than in adults. Recurrence in cervical lymph nodes requires surgical intervention, with the potential risk of postsurgical complications (9-11). Despite the high recurrence rate, juvenile DTC has an overall favorable outcome and prognosis $(10,12)$.

The aim of this study was to analyze the probability of recurrence, prognostic factors, treatment, and outcome of juvenile DTC.

\section{MATERIALS AND METHODS}

\section{Patients}

From January 1977 through December 2012, 1,502 DTC patients were treated with ${ }^{131} \mathrm{I}$ (radioiodine, or radioactive iodine [RAI]) at the Oncology Institute of Vojvodina, Sremska Kamenica, Serbia; 53 of the DTC patients were juvenile patients. The medical records of 51 patients ( 32 girls and 19 boys; mean age, $16.5 \mathrm{y}$; SD, $3.7 \mathrm{y}$; range, 7-20 y) without a history of prior radiation were retrospectively reviewed. Staging for all patients was done in accordance with the International Union Against Cancer-TNM classification system (13). The institutional ethics board approved this retrospective study, and the requirement to obtain informed consent was waived.

\section{Treatment}

Surgical Treatment. Because there was no consensus in Serbia, surgical treatments for patients differed among hospitals. The decision to perform lymph node dissection and the extent of the lymph node dissection were based on the surgeon's judgment at the time. The average time for ablation was $6-8$ mo after the primary surgical procedure. Patients receiving RAI therapy more than 8 mo after the primary surgical procedure were classified as having total thyroidectomy (TTx) or subtotal thyroidectomy (STTx). Ten patients were initially treated with TTx, RAI, and lymph node dissection at the Oncology Institute of Vojvodina.

Ablation with RAI. The Oncology Institute of Vojvodina was the only facility in Serbia treating DTC with RAI through 2006. RAI ablation was administered $4 \mathrm{wk}$ after withdrawal of L-thyroxine (T4) therapy. In prepubertal children, activity was administered on a weight 
basis $(50-100 \mathrm{MBq} / \mathrm{kg})$. However, activity administered after puberty ranged from 3.7 to $7.4 \mathrm{GBq}$ (3.7 $\mathrm{GBq}$ of ${ }^{131} \mathrm{I}$ was used for ablation in patients without nodal or distal metastases [NOM0]; $5.55 \mathrm{GBq}$ of ${ }^{131} \mathrm{I}$ was used in patients with regional and distal metastases [N1M0/ N1M1]).

Follow-up. The median follow-up was 10 y (range, 1-30 y). All patients received L-thyroxine treatment at suppressive doses and were regularly monitored every 3 mo during the first year, every 6 mo during the next $5 \mathrm{y}$, and yearly thereafter. Monitoring included clinical examination, neck ultrasonography, and laboratory testing for thyroglobulin (Tgb), Tgb antibodies, free triiodothyronine, and thyroid-stimulating hormone levels. From 1977 to 2006, Tgb levels were determined with a radioimmunoassay; the normal level after TTx was less than $5 \mu \mathrm{g} / \mathrm{L}$. After 2006, an electrochemiluminescence immunoassay (Roche) was introduced; with this test, the normal level was less than $1.00 \mathrm{ng} / \mathrm{mL}$.

A ${ }^{131}$ I whole-body scan (WBS) with $111 \mathrm{MBq}$ was performed approximately 1 y (8-12 mo) after the initial RAI therapy. Successful ablation was confirmed by the absence of pathologic uptake of ${ }^{131} \mathrm{I}$ and by an undetectable level of $\mathrm{Tgb}(<1 \mathrm{ng} / \mathrm{mL})$. Additional RAI was administered if there was evidence of pathologic activity on the ${ }^{131} \mathrm{I}$ WBS or if there was a persistent elevation of the Tgb level during suppressive therapy.

Patients were classified as having complete remission (no evidence of disease), partial remission (decrease in number of sites and intensity of radioiodine uptake on ${ }^{131}$ I WBS combined with decreasing Tgb levels), recurrent disease (appearance of disease in any patient who had been free of disease for at least $4 \mathrm{mo}$ ), progressive disease (elevation of Tgb levels or increased lesion size or sites), or stable disease (no apparent change in tumor size or sites or Tgb levels).

Patients classified as having recurrent neck disease underwent ultrasound examination and fine-needle aspiration, and the tissue cytology was identified. Patients for whom relapse was confirmed underwent additional surgery (tumor removal or lymphadenectomy) or additional radioiodine therapy (activity of $5.55 \mathrm{GBq}$ ). In patients with a partial response or progressive disease in the lungs, additional RAI was administered as necessary at follow-up. Whole-body or blood dosimetry calculations were not performed for any radioiodine treatment for persistent or recurrent disease.

\section{Statistical Analysis}

The probability of recurrence and the influence of prognostic factors were estimated with the Kaplan-Meier method. The significance of differences was analyzed by use of the log-rank test with statistical software (SPSS version 13; SPSS Inc.). A $P$ value of less than 0.05 was considered significant.

\section{RESULTS}

\section{Demographics, Histology, and Clinical Presentation}

Demographics, histology, and clinical presentation are shown in Table 1. Patients who were 16-20 y old and those with PTC represented the largest groups of patients $(63 \%$ and $86 \%$, respectively); the female-to-male ratio was $1.7: 1$, and tumor multifocality appeared in $23.5 \%$ of patients. At presentation, $69 \%$ of patients had regional lymph node metastases and $13.7 \%$ of patients had distant metastases associated with regional metastases.

\section{Initial Treatment and Follow-up}

Initial treatments and responses are shown in Table 2. Patients were divided into 3 groups: group 1 had 46 patients ( 1 of whom had external-beam radiation therapy [EBRT]), who received TTx and RAI; group 2 had 2 patients, who received TTx (no RAI); and group 3 had 3 patients, who received STTx (no RAI). Of the 51 patients, 29 received RAI only once. Three patients of these 29
TABLE 1

Demographics, Histology, and Clinical Presentation for 51 Patients

\begin{tabular}{|c|c|c|}
\hline Characteristic & No. of patients & Percentage of patients \\
\hline \multicolumn{3}{|l|}{ Sex } \\
\hline Female & 32 & 60.8 \\
\hline Male & 19 & 39.2 \\
\hline Total & 51 & 100.0 \\
\hline \multicolumn{3}{|l|}{ Age } \\
\hline 8-10 y old & 3 & 5.9 \\
\hline $11-15$ y old & 16 & 31.4 \\
\hline 16-20 y old & 32 & 62.7 \\
\hline Total & 51 & 100.0 \\
\hline \multicolumn{3}{|l|}{ Histology } \\
\hline Papillary & 48 & 94.1 \\
\hline Follicular & 3 & 5.9 \\
\hline Total & 51 & 100.0 \\
\hline \multicolumn{3}{|l|}{ TNM } \\
\hline \multicolumn{3}{|l|}{$\mathrm{T}$} \\
\hline TX & 4 & 7.8 \\
\hline $\mathrm{TX}(\mathrm{m})^{\star}$ & 1 & 2.0 \\
\hline Total TX & 5 & 9.8 \\
\hline $\mathrm{T} 1 \mathrm{a}$ & 4 & 7.8 \\
\hline $\mathrm{T} 1 \mathrm{a}(\mathrm{m})^{\star}$ & 2 & 3.9 \\
\hline $\mathrm{T} 1 \mathrm{~b}$ & 4 & 7.8 \\
\hline $\mathrm{T} 1 \mathrm{~b}(\mathrm{~m})^{*}$ & 2 & 3.9 \\
\hline Total T1 & 12 & 23.4 \\
\hline $\mathrm{T} 2$ & 14 & 27.5 \\
\hline $\mathrm{T} 2(\mathrm{~m})^{\star}$ & 3 & 5.9 \\
\hline Total T2 & 17 & 33.4 \\
\hline T3 & 5 & 9.8 \\
\hline $\mathrm{T} 3(\mathrm{~m})^{\star}$ & 0 & 0 \\
\hline Total T3 & 5 & 9.8 \\
\hline $\mathrm{T} 4 \mathrm{a}$ & 8 & 15.7 \\
\hline $\mathrm{T} 4 \mathrm{a}(\mathrm{m})^{\star}$ & 3 & 5.9 \\
\hline $\mathrm{T} 4 \mathrm{~b}$ & 1 & 2.0 \\
\hline $\mathrm{T} 4 \mathrm{~b}(\mathrm{~m})^{\star}$ & 0 & 0 \\
\hline Total T4 & 12 & 23.6 \\
\hline All T patients & 51 & 100.0 \\
\hline \multicolumn{3}{|l|}{$\mathrm{N}$} \\
\hline NO & 17 & 33.3 \\
\hline $\mathrm{N} 1 \mathrm{a}$ & 8 & 15.7 \\
\hline $\mathrm{N} 1 \mathrm{~b}$ & 26 & 51.0 \\
\hline All N patients & 51 & 100.0 \\
\hline \multicolumn{3}{|l|}{ M } \\
\hline MO & 44 & 86.3 \\
\hline M1 & 7 & 13.7 \\
\hline All M patients & 51 & 100.0 \\
\hline \multicolumn{3}{|l|}{ Clinical stage } \\
\hline I & 44 & 86.3 \\
\hline II & 7 & 13.7 \\
\hline Total & 51 & 100.0 \\
\hline
\end{tabular}

initially underwent STTx but relapsed during follow-up; after the recurrence appeared, they were retreated with TTx followed by RAI. After the initial treatment, different responses were detected in the patients: 31 patients (including 6 patients with recurrent disease) achieved complete remission, 14 patients achieved partial remission, and 1 patient had progressive disease. Eleven patients $(21.6 \%)$ had relapses during the follow-up period. In retreated patients, RAI was repeated once in 12 patients, twice 
TABLE 2

Initial Treatments and Responses for 51 Patients

\begin{tabular}{|c|c|c|c|c|c|}
\hline \multirow[b]{2}{*}{ Initial treatment } & \multirow[b]{2}{*}{$\begin{array}{l}\text { No. of } \\
\text { patients }\end{array}$} & \multicolumn{3}{|c|}{$\begin{array}{l}\text { No. of patients with following } \\
\text { response to initial treatment: }\end{array}$} & \multirow[b]{2}{*}{$\begin{array}{l}\text { No. of patients with } \\
\text { recurrent disease* }\end{array}$} \\
\hline & & $\begin{array}{l}\text { Complete } \\
\text { remission }\end{array}$ & $\begin{array}{l}\text { Partial } \\
\text { remission }\end{array}$ & $\begin{array}{l}\text { Progressive } \\
\text { disease }\end{array}$ & \\
\hline \multicolumn{6}{|l|}{ Group 1} \\
\hline TTx + RAl & 17 & 14 & 3 & 0 & 0 \\
\hline TTX + CLND + RAI & 23 & 12 & 10 & 1 & 5 \\
\hline TTx + CLND + EBRT + RAI & 1 & 1 & 0 & 0 & 1 \\
\hline TTx + MLND + RAI & 1 & 1 & 0 & 0 & 0 \\
\hline TTx + CLND + MLND + RAI & 4 & 3 & 1 & 0 & 0 \\
\hline Total & 46 & 31 & 14 & 1 & 6 \\
\hline \multicolumn{6}{|l|}{ Group 2} \\
\hline TTx + CLND & 2 & 2 & 0 & 0 & 2 \\
\hline \multicolumn{6}{|l|}{ Group 3} \\
\hline \multicolumn{6}{|l|}{ STTx } \\
\hline LO + CLND + MLND & 1 & 1 & 0 & 0 & 1 \\
\hline TUM & 1 & 1 & 0 & 0 & 1 \\
\hline PT & 1 & 1 & 0 & 0 & 1 \\
\hline Total & 3 & 3 & 0 & 0 & 3 \\
\hline
\end{tabular}

${ }^{*}$ Recurrent disease was disease appearing during follow-up, after remission was achieved in patients who were treated with TTx and RAI or after several years in patients who underwent less intensive initial treatment (TTx or STTx).

LO = lobectomy; TUM = tumorectomy; PT = partial thyroidectomy.

in 3 patients, 3 times in 2 patients, 4 times in 3 patients, 5 times in 1 patient, and 9 times in 1 patient; total cumulative activities were 7.4-35.25 GBq.

\section{Recurrent Disease}

Recurrent disease was observed in 6 patients who initially received TTx and RAI (plus cervical lymph node dissection [CLND] in 5 patients and plus CLND and EBRT in 1 patient), in 2 patients who received TTx (plus CLND), and in 3 patients who received STTx (plus CLND and MLND) (Table 3).

The median time of recurrence was $52 \mathrm{mo}$ (range, 12-180 mo). The probabilities of recurrence were $16.7 \%$ at $5 \mathrm{y}, 22.3 \%$ at $10 \mathrm{y}$, and $33.3 \%$ at 15 and $23 \mathrm{y}$ after the initial treatment (Fig. 1). Recurrence was significantly influenced by age, initial treatment, and tumor multifocality $(P=0.001, P=0.0001$, and $P=0.011$, respectively) (Figs. 2, 3, and 4, respectively). However, no significant difference was associated with the following prognostic factors: sex, nodal metastases at presentation, distal metastases at presentation, histologic type of the tumor, $\mathrm{T}$ stage, and clinical stage $(P=0.180, P=0.786, P=0.796, P=0.944, P=0.352$, and $P=0.729$, respectively). Recurrent disease was detected in the thyroid bed on 2 occasions in 1 patient. A second recurrence also involved bilateral cervical lymph nodes. Metastatic cervical lymph nodes alone occurred in 5 patients ( 2 unilateral and 3 bilateral; distant sites in 3 patients [lungs] and combined sites in 2 patients [lungs and brain; cervical lymph nodes and lungs]) (Table 3). Recurrence occurred twice, after 4 and $12 \mathrm{y}$, in 1 patient and after 7 , 22 , and almost 25 y (after initial complete remission was achieved) in another patient. Additional treatments in 11 patients with recurrence included surgery or surgery followed by RAI, as recommended by the Tumor Board (Table 3 ). The cumulative activities in patients with relapse were $3.7-40 \mathrm{GBq}$ of ${ }^{131} \mathrm{I}$.

One patient (patient 2; Table 3) merits special mention (Figs. 5 and 6). At age 8, she underwent surgery and EBRT (115 Gy to the neck and 4 doses of ${ }^{131}$ I). She presented at the Oncology Institute of Vojvodina 6 y later with lung metastases and was treated with 6 more doses of ${ }^{131} \mathrm{I}$ (for a total of 10 doses [40 GBq] over several years). Although she had evidence of early pulmonary fibrosis, she received the last 2 radioiodine treatments. She lived 11 more years without clinical disability and had 2 complete pregnancies. In summary, she lived $24 \mathrm{y}$ after the initial diagnosis and died recently of recurrent brain metastases.

\section{Outcome}

The patients' status after the initial treatments and the final outcomes are shown in Table 4. During the follow-up period, 25 of 36 patients with initial complete remission did not relapse. Another 14 patients with initial partial remission were retreated; 12 patients achieved complete remission, 1 patient achieved partial remission ( $\mathrm{Tgb}, 3.6 \mathrm{ng} / \mathrm{mL}$, on L-thyroxine therapy), and 1 patient had stable disease (Tgb, $2.6 \mathrm{ng} / \mathrm{mL}$, on L-thyroxine therapy). A patient with progressive disease achieved complete remission. One patient with complete remission died from another cause of death. Nine of 11 patients with relapse achieved complete remission, 1 patient achieved partial remission (Tgb, $4.6 \mathrm{ng} / \mathrm{mL}$ on LT4 therapy), and disease-related death occurred in 1 patient. Among all studied patients, complete remission was achieved in 46 patients, partial remission was achieved in 2 patients, 1 patient had stable disease, disease-related death occurred in 1 patient, and another cause of death occurred in 1 patient. Eleven female patients (cumulative activity, 3.7-40 GBq of $\left.{ }^{131} \mathrm{I}\right)$ ultimately had children ( 8 delivered 2 children, and 3 had 1 child); complete remission was achieved in 9, partial remission was achieved in 1, and diseaserelated death occurred in 1 .

\section{DISCUSSION}

In the absence of exposure to external radiation, thyroid cancer is rather infrequent in patients 20 y old or younger $(2 \%-10 \%)(14-16)$. 


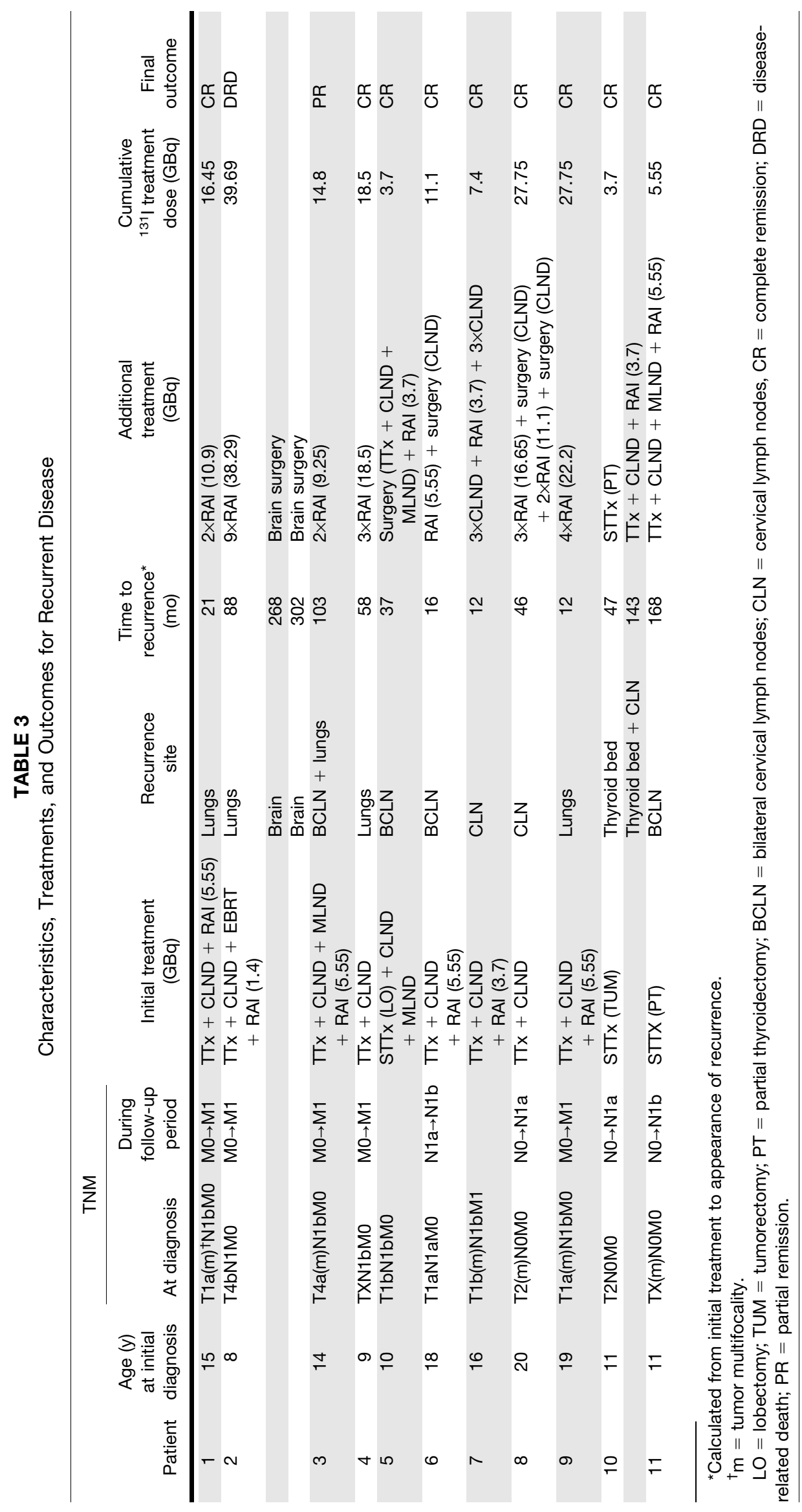

Recurrent Juvenile Thyroid Carcinoma - Mihailovic et al. 


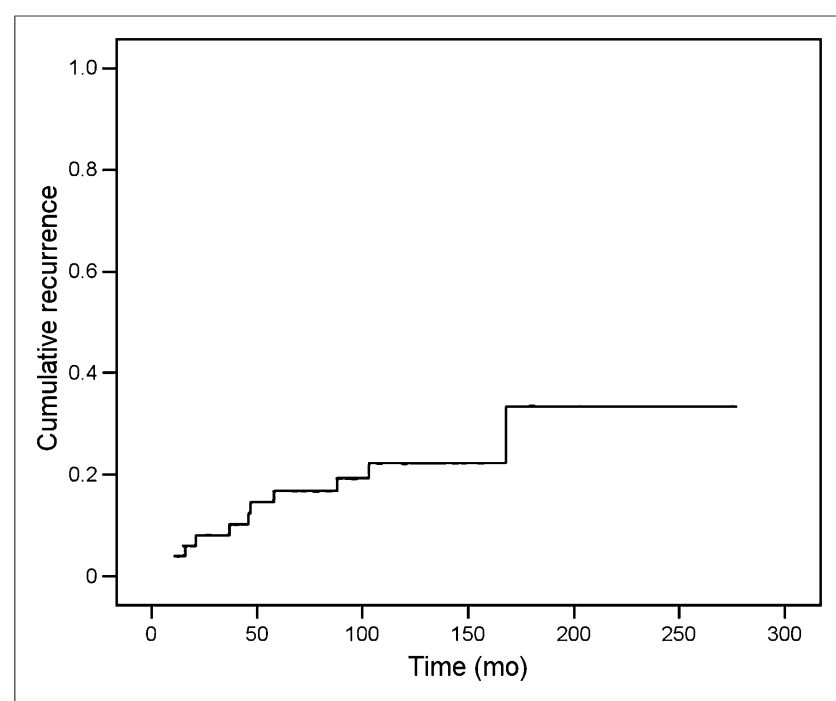

FIGURE 1. Probability of recurrence.

In our experience, there was a $3.5 \%$ incidence of juvenile DTC, and recurrent disease was detected in $22 \%$ of patients. These data correlate with previously reported recurrence rates of $19 \%-24 \%$ $(10,15,16)$. However, wider ranges $(11 \%-32 \%)$ have been reported $(12,17-21)$, as have ranges as high as $39 \%-46 \%(5,22,23)$.

Our results indicated that 3 predictive factors significantly increased the risk of recurrent disease (either local, regional, or distant recurrent site): age, tumor multifocality, and initial treatment. It was reported previously that age at diagnosis is a strong predictor of cancer relapse $(11,16,20,24)$. Demidchik et al. (20) studied 740 children and found that age and multifocality strongly affected recurrent nodal disease, findings that correlate with our results. Enomoto et al. (16) studied 142 pediatric patients with DTC, with a median follow-up of $22 \mathrm{y}$, and reported that an age of less than 16 y was a risk factor for recurrent disease, in addition to a familial history of thyroid cancer, tumor size, large lymph node metastases, extranodal invasion, and initial distant metastases. Other authors have reported that younger children have a higher risk of relapse (25-27). In the present study, patients

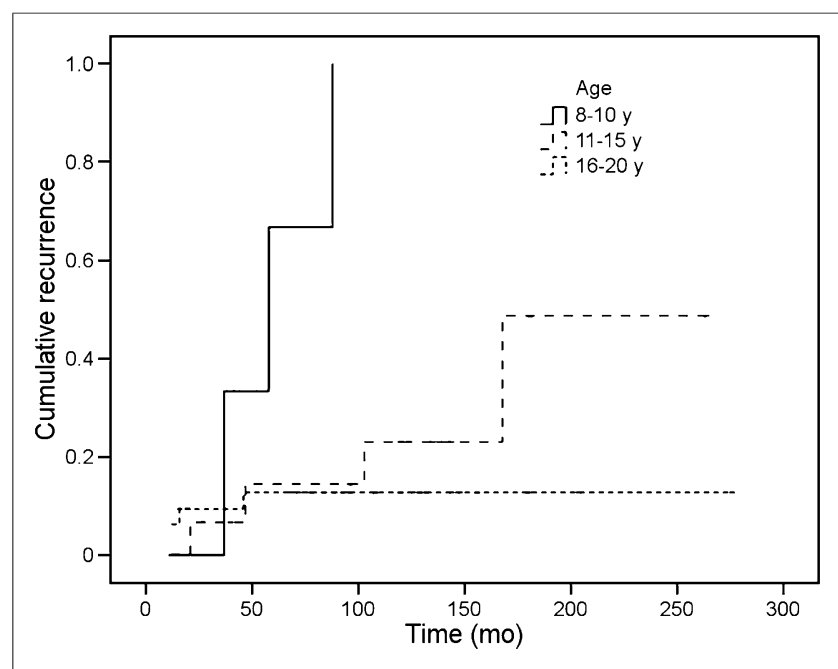

FIGURE 2. Influence of age on probability of recurrence. Data are for patients aged 8-10 y, patients aged 11-15 y, and patients aged 16-20y.

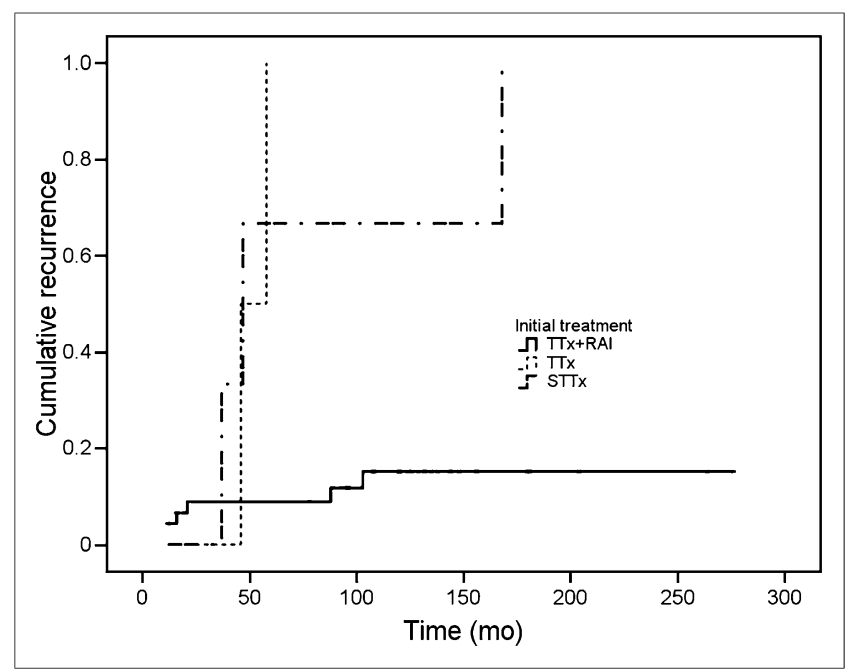

FIGURE 3. Influence of initial treatment on probability of recurrence. Data are for patients who underwent $T T x$ only $(T T x)$, patients who underwent STTx only (STTX), and patients who underwent TTx and RAI ablation (TTx+RAI).

in group 1 ( $<10$ y old) had the worst prognosis; all relapsed. The probabilities of recurrence after 5 y were $66.7 \%$ in group $1,14.4 \%$ in group 2, and $12.7 \%$ in group 3 . In group 2, the probabilities of recurrence after 10 and 15 y were $23 \%$ and $48.7 \%$, respectively; in group 3, the probability of recurrence at 10, 15, 20, and $23 \mathrm{y}$ after the initial treatment was $12.7 \%$. The difference in the probabilities of recurrence between patients in group 1 and patients in group 3 was highly significant $(P=0.001)$. Nevertheless, some authors have reported that age is not a significant risk factor for recurrent disease $(19,28)$.

Another factor that was strongly predictive of recurrent disease was the type of initial treatment. Patients who underwent TTx and RAI had a lower probability of recurrence than those who initially underwent less intense therapy (STTx) $(P=0.0001)$. Although there is some controversy about the influence of the extent of initial treatment on recurrence in juvenile DTC $(9,19,20,29)$, our

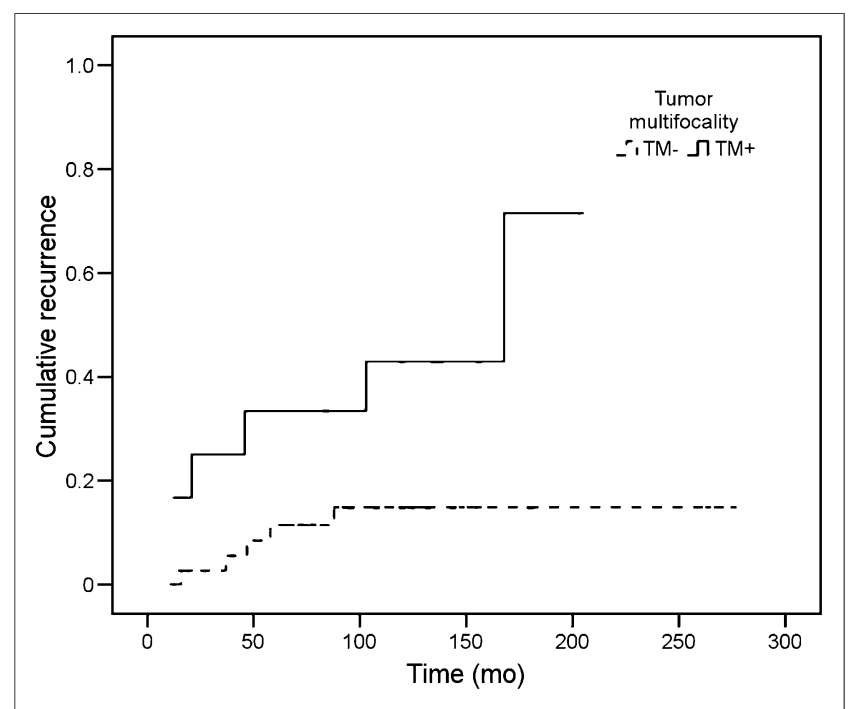

FIGURE 4. Influence of tumor multifocality on probability of recurrence. Data are for patients with multifocal tumors $(\mathrm{TM}+)$ and patients without multifocal tumors (TM-). 


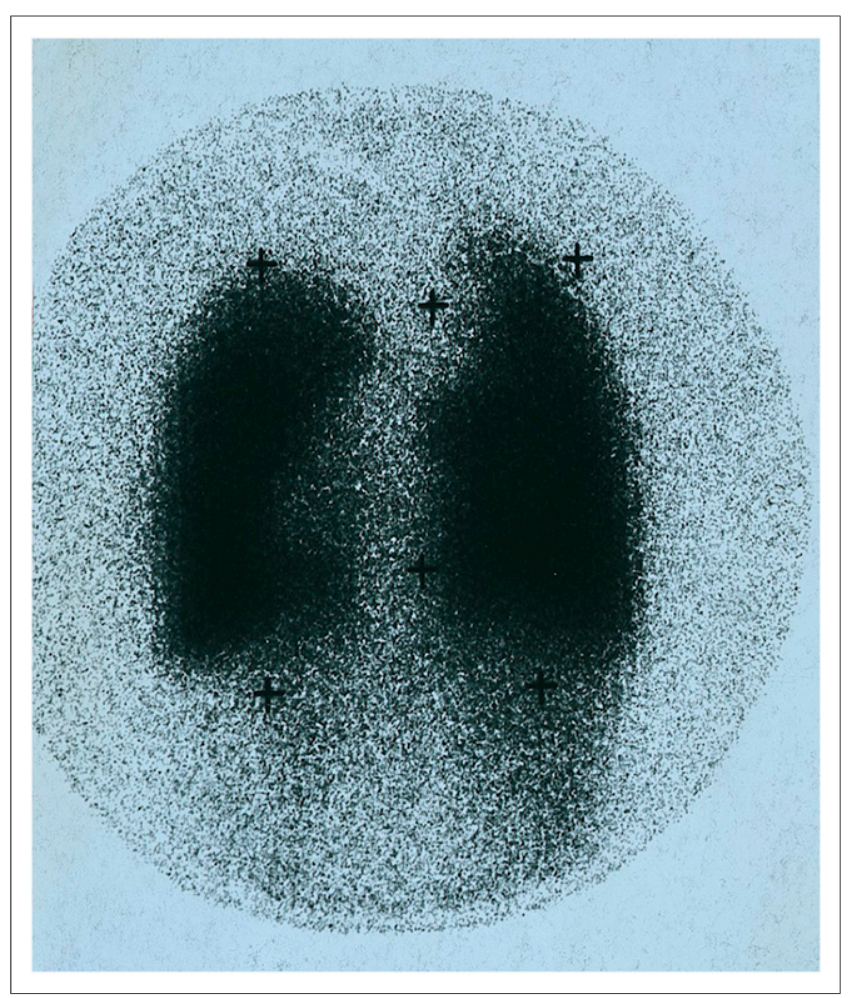

FIGURE 5. ${ }^{131} \mathrm{I}$ WBS of posterior chest after treatment. Thyroid-stimulating hormone level was $40 \mathrm{mU} / \mathrm{L}$, and Tgb level was $850 \mu \mathrm{g} / \mathrm{L}$. 14-y-old girl was seen 6 y after initial diagnosis of juvenile papillary thyroid carcinoma. She had been treated with surgery, EBRT (115 Gy), and 4 doses of ${ }^{131}$ I.

results confirmed that TTx followed by RAI reduced the risk of relapse; $67.4 \%$ of patients who initially underwent TTx followed by RAI (group 1) achieved complete remission, 30.4\% achieved partial remission, and $2.2 \%$ had progressive disease. During the follow-up period, recurrence developed in 11 of 51 patients $(21.6 \%)$ (6/11 patients in group 1 and 5/11 patients in groups 2 and 3).

Other authors have reported that the extent of initial surgical treatment is a predictive factor for recurrence. Jarzab et al. (27) showed that TTx was associated with $97 \%$ recurrence-free survival, whereas lobectomy resulted in $59 \%$ and $85 \%$ recurrences after 5 and $10 \mathrm{y}$, respectively. Treatment with less than TTx increased the risk of relapse by a factor of 10 . In addition, subsequent RAI strongly affected the relapse rate, decreasing the relative risk of recurrence by a factor of 5 . Popovtzer et al. (18) concluded that TTx led to a significantly lower recurrence rate (7.5\%) than hemithyroidectomy $(38 \%)(P<0.005)$. Nevertheless, some authors have reported no relationship between the extent of surgery and the recurrence rate $(9,24,30)$.

Recurrent disease is frequent in multicentric PTC $(11,29,31)$. Some authors have found that tumor multifocality increases the risk of regional recurrence, metastases, and poor outcomes (31). In a series of 1,682 PTCs, patients with multifocal tumors had a significantly higher recurrence rate than those with unifocal tumors (20.2\% vs. $13 \% ; P=0.0008)(31)$. These data are consistent with our results, which indicated that tumor multifocality is a third predictive factor that significantly influences the probability of recurrence $(P=0.011)$.

In our series, lymph node involvement at presentation was observed in $69 \%$ of patients. However, there was no correlation between lymph node metastases at presentation and risk of recurrence. This finding is consistent with 1 previous report (22) but not with others $(28,30,32)$. Some authors have reported a lower or higher incidence of initial lymph node involvement, ranging from $40 \%$ to $80 \%(5,12,17,18,20,22,32,33)$. In contrast, La Quaglia et al. (34) detected initial nodal involvement in $90 \%$ of patients who presented with distant metastases. Lung metastases were diagnosed initially in $14 \%$ of our patients; this finding correlates with the previously reported rate of $15 \%(5,35)$. There are other studies with discordant rates, such as the low rate of $2.3 \%$ (20), $6 \%-25 \%(8,10,12,15,18,20,21,23,35)$, and the high rate of $40 \%(21)$.

Overall, thyroid cancer in children and adolescents has an excellent prognosis, with $97 \%-99 \%$ survival at 10 y $(15,18,20)$ and $90 \%-95 \%$ survival at $20 \mathrm{y}(7,9,18,36)$. Moreover, Hogan et al. (8) reported $90 \%$ survival at $30 \mathrm{y}$, and Hay et al. (12) detected $98 \%$ survival at 30-50 y after surgery. In agreement with those data, excellent disease-specific survival (98\%) during the follow-up period (1-30 y) was found in the present study. Other authors have reported no disease-related deaths $(5,21,22,30)$. Recurrence-free survival rates of $70 \%-80 \%$ and $73 \%$ at $5 \mathrm{y}(10,15,21,34,37)$ and $10 \mathrm{y}$ (15), respectively, have been reported. In the present study, slightly longer recurrence-free survival rates were found: $83.3 \%$ at $5 \mathrm{y}, 77.7 \%$ at $10 \mathrm{y}$, and $66.7 \%$ at 15 and $23 \mathrm{y}$ after initial treatment.

The overall outcomes in our patients were excellent: $90.2 \%$ achieved complete remission, $3.92 \%$ achieved partial remission, $1.96 \%$ had stable disease, disease-related death occurred in $1.96 \%$, and another cause of death occurred in $1.96 \%$. In agreement with our results, Chazot et al. (30) reported that $90 \%$ of patients achieved remission after a median follow-up of $5 \mathrm{y}$, whereas Giuffrida et al. (5) reported poorer results $(79 \%$ of patients achieved complete remission and $21 \%$ had residual disease).

Optimal surgical treatment and subsequent RAI are still considered controversial and remain a matter of discussion. Because thyroid carcinoma spreads in an intraglandular manner and can

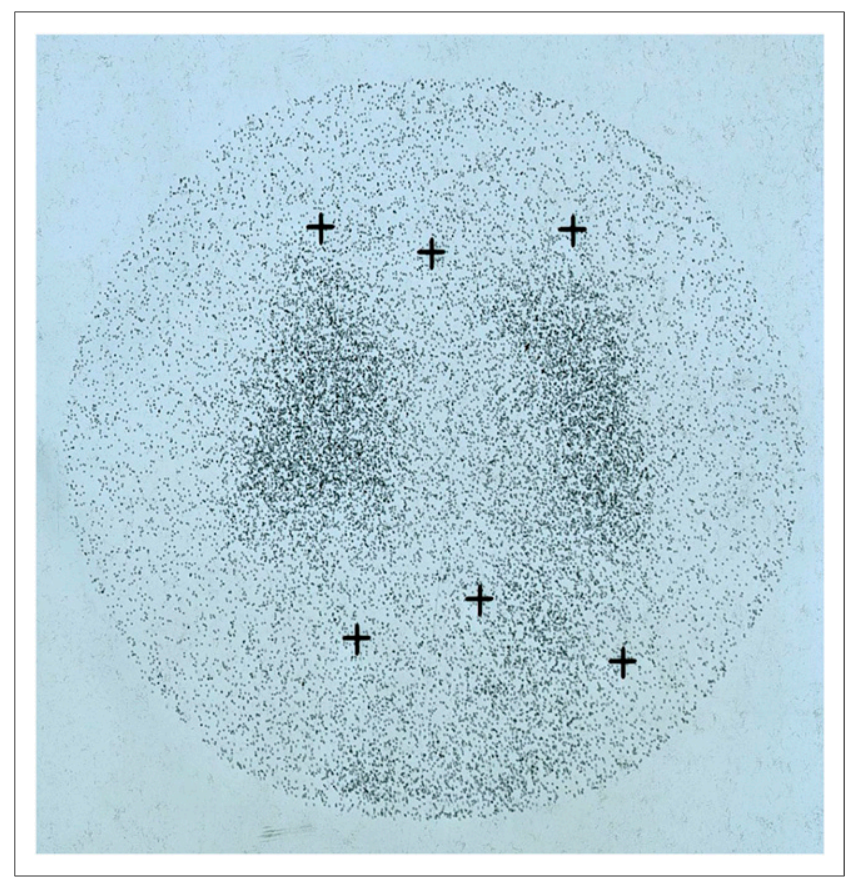

FIGURE 6. ${ }^{131}$ I WBS of anterior chest after diagnostic ${ }^{131} \mid$ dose (thyroid-stimulating hormone level, $45 \mathrm{mU} / \mathrm{L}$; Tgb level, $13 \mu \mathrm{g} / \mathrm{L}$ ) of same patient as in Figure 5 but 2 y later. 
TABLE 4

Final Outcomes for 51 Patients

\begin{tabular}{|c|c|c|c|c|c|c|}
\hline \multirow[b]{3}{*}{$\begin{array}{c}\text { Patient status after initial } \\
\text { treatment }\end{array}$} & \multirow[b]{3}{*}{$\begin{array}{l}\text { No. of } \\
\text { patients }\end{array}$} & \multicolumn{5}{|c|}{ Final outcome } \\
\hline & & \multicolumn{3}{|c|}{ Living patients $(n=49)$} & \multicolumn{2}{|c|}{ Lethal outcome $(n=2)$} \\
\hline & & $\begin{array}{l}\text { Complete } \\
\text { remission }\end{array}$ & $\begin{array}{l}\text { Partial } \\
\text { remission }\end{array}$ & $\begin{array}{l}\text { Stable } \\
\text { disease }\end{array}$ & $\begin{array}{l}\text { Disease-related } \\
\text { death }\end{array}$ & $\begin{array}{c}\text { Other cause of } \\
\text { death }\end{array}$ \\
\hline Complete remission & 25 & 24 & 0 & 0 & 0 & 1 \\
\hline Recurrent disease & 11 & 9 & $1^{\star}$ & 0 & 1 & 0 \\
\hline Total & 36 & 33 & 1 & 0 & 1 & 1 \\
\hline Partial remission & 14 & 12 & $1^{\dagger}$ & $1 \ddagger$ & 0 & 0 \\
\hline Progressive disease & 1 & 1 & 0 & 0 & 0 & 0 \\
\hline Total & 51 & 46 & 2 & 1 & 1 & 1 \\
\hline \multicolumn{7}{|c|}{ 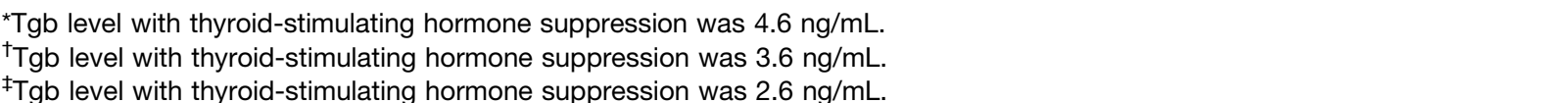 } \\
\hline
\end{tabular}

show multifocality, thyroid remnants are at risk for local relapse. Some authors have suggested a radical surgical approach as the initial surgical treatment performed by highly experienced surgeons $(5,22)$. Enomoto et al. (16) suggested that RAI should be used only in patients with large lymph nodes and distant metastases at diagnosis. Treatment with TTx, lymph node dissection, and RAI is considered appropriate for preventing recurrence $(18,20,21,36)$. Chow et al. (38) reported that RAI reduced the risk of both locoregional and distant recurrences. They did not detect secondary malignancy or impairment of fertility and pregnancy outcomes. In contrast, Hay et al. (12) found no statistically significant difference between survival after surgery alone and survival after surgery followed by RAI.

Our data support the conclusion that TTx (with lymph node dissection, if necessary) followed by RAI will prevent relapse or decrease the relapse rate. There were no adverse effects in subsequent pregnancies in patients treated with RAI. Eleven female patients (22\% of all treated patients) subsequently had children. Despite the high cumulative activity in some patients, secondary malignancy was not detected as long as $30 \mathrm{y}$ after treatment.

\section{CONCLUSION}

Younger age at diagnosis, tumor multifocality, insufficient primary surgery, and lack of radioiodine ablation are risk factors for recurrent disease in juvenile DTC. TTx followed by RAI appears to be an appropriate initial treatment. Recurrent disease should be treated with surgery or radioiodine treatment until remission. Both initial treatment with radioiodine and retreatment with radioiodine are safe, with no adverse effects on fertility or secondary malignancy.

\section{DISCLOSURE}

The costs of publication of this article were defrayed in part by the payment of page charges. Therefore, and solely to indicate this fact, this article is hereby marked "advertisement" in accordance with 18 USC section 1734 . No potential conflict of interest relevant to this article was reported.

\section{ACKNOWLEDGMENTS}

We gratefully acknowledge the contributions of the late Professor Ljubomir Stefanovic, MD, PhD, the Founder and Former
Head, Department of Nuclear Medicine, Oncology Institute of Vojvodina, Sremska Kamenica, Serbia, and Medical Faculty Novi Sad, University of Novi Sad, Novi Sad, Serbia. His analysis of the data as well as his wisdom contributed to the substance of this article.

\section{REFERENCES}

1. Hung W, Sarlis NJ. Current controversies in the management of pediatric patients with well-differentiated nonmedullary thyroid cancer: a review. Thyroid. 2002;12:683-702.

2. Ries LAG, Melbert D, Krapcho M, et al., eds. SEER Cancer Statistics Review, 1975-2004. Bethesda, MD: National Cancer Institute; 2007.

3. Cancer incidence and mortality in central Serbia, 1999-2010. Institute of Public Health of Serbia website. Available by searching for the specific year of the report at: http://www.batut.org.rs/index.php. Accessed March 28, 2014.

4. Cancer registry data of Oncology Institute of Vojvodina [unpublished database]. Sremska Kamenica, Serbia: Oncology Institute of Vojvodina; 2010.

5. Giuffrida D, Scollo C, Pellegriti G, et al. Differentiated thyroid cancer in children and adolescents. J Endocrinol Invest. 2002;25:18-24.

6. Zimmerman D, Hay ID, Gough IR, et al. Papillary thyroid carcinoma in children and adults: long-term follow-up of 1039 patients conservatively treated at one institution during three decades. Surgery. 1988;104:1157-1166.

7. Brink JS, van Heerden JA, McIver B, et al. Papillary thyroid cancer with pulmonary metastases in children: long term prognosis. Surgery. 2000;128:881-886.

8. Hogan AR, Zhuge Y, Perez EA, et al. Pediatric thyroid carcinoma: incidence and outcome in 1753 patients. J Surg Res. 2009;156:167-172.

9. Newman KD, Black T, Heller G, et al. Differentiated thyroid cancer: determinants of disease progression in patients $<21$ years of age at diagnosis: a report from the Surgical Discipline Committee of the Children's Cancer Group. Ann Surg. 1998;227:533-541.

10. Welch Dinauer CA, Tuttle RM, Robie DK, et al. Clinical features associated with metastasis and recurrence of differentiated thyroid cancer in children, adolescents and young adults. Clin Endocrinol (Oxf). 1998;49:619-628.

11. Grigsby PW, Gal-or A, Michalsky JM, et al. Childhood adolescent thyroid carcinoma. Cancer. 2002;95:724-729.

12. Hay ID, Gonzalez-Losada T, Reinalda MS, et al. Long-term outcome in 215 children and adolescents with papillary thyroid cancer treated during 1940 through 2008. World J Surg. 2010;34:1192-1202.

13. Sobin LH, Gospodarowicz MK, Wittekind C, eds. TNM Classification of Malignant Tumours. 7th ed. West Sussex, England: Wiley-Blackwell Publishing; 2010:58-62.

14. Bernstein L, Gurney JG. Carcinomas and other malignant epithelial neoplasms: ICCC XI. In: Ries LAG, Smith MA, Gurney JG, et al., eds. Cancer Incidence and Survival Among Children and Adolescents: United States SEER Program 1975-1995. Bethesda, MD: National Cancer Institute; 1999:139-147. Publication 99-4649.

15. Huang $\mathrm{CH}$, Chao TC, Hseuh $\mathrm{C}$, et al. Therapeutic outcome and prognosis in young patients with papillary and follicular thyroid cancer. Pediatr Surg Int. 2012;28:489-494. 
16. Enomoto Y, Enomoto E, Uchino S, et al. Clinical features, treatment, and longterm outcome of papillary thyroid cancer in children and adolescents without radiation exposure. World J Surg. 2012;36:1241-1246.

17. Papendieck P, Grunero-Papendieck L, Venara M, et al. Differentiated thyroid carcinoma: presentation and follow-up in children and adolescents. J Pediatr Endocrinol Metab. 2011;24:743-748.

18. Popovtzer A, Shpitzer T, Bahar G, Feinmesser R, Segal K. Thyroid cancer in children: management and outcome experience of a referral center. Otolaryngol Head Neck Surg. 2006;135:581-584.

19. Handkiewicz-Junak D, Wloch J, Roskosz J, et al. Total thyroidectomy and adjuvant radioiodine treatment independently decrease locoregional recurrence risk in childhood and adolescent differentiated thyroid cancer. J Nucl Med. 2007;48: 879-888.

20. Demidchik YE, Demidchik EP, Reiners C, et al. Comprehensive clinical assessment of 740 cases of surgically treated thyroid cancer in children of Belarus. Ann Surg. 2006;243:525-532.

21. Lazar L, Lebenthal Y, Steinmetz A, Yackobovitch-Gavan M, Phillip M. Differentiated thyroid carcinoma in pediatric patients: comparison of presentation and course between pre-pubertal children and adolescents. J Pediatr. 2009;154:708-714.

22. Dardas M, Abboud M, Salti I, et al. Thyroid cancer in Lebanese children and adolescents: a 15-year experience at a single institution. Pediatr Hematol Oncol. 2009;26:439-447.

23. Landau D, Vini L, A'Hern R, Harmer C. Thyroid cancer in children: the Royal Marsden Hospital experience. Eur J Cancer. 2000;36:214-220.

24. Alessandri AJ, Goddard KJ, Blair GK, et al. Age is the major determinant of recurrence in pediatric differentiated thyroid carcinoma. Med Pediatr Oncol. 2000;35:41-46.

25. Farahati J, Bucsky P, Parlowsky T, Mader U, Reiners C. Characteristics of differentiated thyroid carcinoma in children and adolescents with respect to age, gender, and histology. Cancer. 1997;80:2156-2162.

26. LaQuardia MP, Corbally MT, Heller G, et al. Recurrence and morbidity in differentiated thyroid cancer in children. Surgery. 1998;104:1149-1156.
27. Jarzab B, Handkiewicz Junak D, Wloch J, et al. Multivariate analysis of prognostic factors for differentiated thyroid carcinoma in children. Eur J Nucl Med. 2000;27:833-841.

28. Palmer BA, Zarroug AE, Poley RN, Kollars JP, Moir CR. Papillary thyroid carcinoma in children: risk factors and complications of disease recurrence. J Pediatr Surg. 2005;40:1284-1288.

29. Spinelli C, Bertocchini A, Antonelli A, Miccoli P. Surgical therapy of the thyroid papillary carcinoma in children: experience with 56 patients $\leq 16$ years old. J Pediatr Surg. 2004;39:1500-1505.

30. Borson-Chazot F, Causeret S, Lifante JC, Augros M, Berger N, Peix JL. Predictive factors for recurrence from a series of 74 children and adolescents with differentiated thyroid cancer. World J Surg. 2004;28:1088-1092.

31. Lin JD, Chao TC, Hsueh C, Kuo SF. High recurrent rate of multicentric papillary thyroid carcinoma. Ann Surg Oncol. 2009;16:2609-2616.

32. Wada N, Sugino K, Mimura T, et al. Pediatric differentiated thyroid carcinoma in stage I: risk factor analysis for disease free survival. BMC Cancer. 2009;9:306.

33. Bargren AE, Meyer-Rochow GY, Delbridge LW, Sidhu SB, Chen H. Outcomes of surgically managed pediatric thyroid cancer. J Surg Res. 2009;156:70-73.

34. La Quaglia MP, Black T, Holcomb GW, et al. Differentiated cancer: clinical characteristics, treatment, and outcome in patients under 21 years of age who present with distant metastases-a report from the Surgical Discipline Committee of the Children's Cancer Group. J Pediatr Surg. 2000;35:955-959.

35. O'Gorman CS, Hamilton J, Rachmiel M, et al. Thyroid cancer in childhood: a retrospective review of childhood course. Thyroid. 2010;20:375-380.

36. Beasley NJ, Lee J, Eski S, et al. Impact of nodal metastases on prognosis in patients with well differentiated thyroid cancer. Arch Otolaryngol Head Neck Surg. 2002;128:825-828.

37. Leboulleux S, Baudin E, Hartl DW, Travagli JP, Schlumberger M. Follicular cellderived thyroid cancer in children. Horm Res. 2005;63:145-151.

38. Chow SM, Law SCK, Mendenhall WM, Au SK, Yau S, Lau WH. Differentiated thyroid carcinoma in childhood and adolescence: clinical course and role of radioiodine. Pediatr Blood Cancer. 2004;42:176-183. 